\title{
Development of strategic human source management model for small and medium enterprises in Thailand's new normal life
}

\author{
Wanchai Panjan ${ }^{1 *}$, Orathai Chuacharoen ${ }^{1}$, Passakorn Ruangvanit ${ }^{1}$, Walaipon \\ Arjareewattana ${ }^{1}$, Anek Pradittharom ${ }^{1}$ and Kitti Chunhasriwong ${ }^{1}$ \\ ${ }^{1}$ Ramkhamhaeng University, Thailand
}

\begin{abstract}
The purposes of this research were to study the condition and strategic human resource management and to develop a strategic human resource management model for small and medium enterprises(SMEs) in the new normal life era. The research model was mixed research by collecting data from the sample group in 2parts: (1) a sample group from qualitative research by interviewing 10 entrepreneurs or executives of SMEs and focus groups consisted of 19 experts, and (2) a quantitative research sample group, 400 participants which is entrepreneurs or executives of SMEs. The research tools were interview form and questionnaire. Data were analyzed by statistics: percentage, mean, standard deviation, and Exploratory Factor Analysis: EFA. The findings revealed that: 1) Strategic human resource management for small and medium-sized enterprises (SMEs) in the new normal life era, it was found that it can be composed of all 5components: (1)human resource planning,(2)human resource recruitment and selection, (3) employee retention, (4)human resource utilization, and (5)human resource development. The Eigen Value after rotation ranged from 6.86-12.84, the percentage variance was from $11.42-22.43$ and the cumulative percentage of variance was $85.78 \%$. 2)The result of developing a strategic human resource management model for small and medium enterprises (SMEs) in the new normal life era that must be considered from the goals of the organization by analyzing the organization's resources from 2parts: Resource requirements and available resources of SMEs in the new normal life era. It can lead to the transformation of resources in line with SMEs operations in the new life era and implement Change Management in the strategic human resource management process from the components of strategic human resource management for SMEsin the new normal life era with 5 main components and 15 sub-components.
\end{abstract}

\section{Introduction}

Human resources management is a very important function in every organization because it reflects the success of the organization's activities. Meanwhile, two of thirds strategic human resource management is the preparation and implementation of strategies.

* Corresponding author: chaipanjan@rumail.ru.ac.th 
Moreover, human resource management strategies can be successful if senior management pays serious attention[1]. It can be said that the human resource of an organization is clearly identified as the key factor that can give a company a sustainable competitive advantage amid today's highly competitive business world. An organization that can influence behaviour and motivate employees through the human resource management system will be an organization that can increase the performance of the organization and lead to the survival of the organization [2].

Small and medium enterprises (SMEs) are considered suitable enterprises with flexibility to adapt to the general situation of Thailand. It is also an enterprise that does not require much capital to start operations. The key point is that SMEs are a source of employment that generates income for citizens and is linked to large businesses and other manufacturing sectors. It can be regarded as an important engine in driving the country's economy to expand and grow sustainably. Which is the key to national reforms according to the 20-year national strategy of Thailand [3].However, according to a report by the Office of Small and Medium Enterprises Promotion (OSMEP) in 2018, there were 3,077,822 SMEs in Thailand, of which 100 were small enterprises. 99.33each of the total number of enterprises The country has increased income The GDP of SMEsin 2018was worth up to $7,013,971$ million baht or $43.0 \%$ of GDP in the country which creates a lot of employment. In 2019, 3,105,096 people were employed [4].

In the situation of the outbreak of the novel coronavirus (Covid-19) has affected the economy in a wide range.The COVID-19 crisis was affect more than 1.33 million SMEs, Over 4 million workers are unemployed. If the protracted situation continues until the end of 2021, SMEs will lose over 350 billion baht in revenue. Direct impacts occur on key business mechanisms, namely the tourism sector, where the supply chain extends to other businesses such as restaurant, spa, small accommodation and transportation services. Including the number of tourists who consume products in Thailand that have decreased significantly. The indirect effect is caused by consumers reducing their purchases and turning to online shopping instead [5]. Therefore, SMEs have to speed up to adapt themselves to the New normal life era to solve this problems. Now, Strategic human resource management is an important process. It is difficult to get talented people or even retention a talent peoples. Strategic human resource management for SMEs in the New normal life era aims to change the business management model that focuses on human resources in terms of systematic human resource management. Therefore, strategic human resource management is both a strategy and a business function that will contribute to the effectiveness and productivity of the overall achievement of organization' goals [6].

Based on the background and importance of the above problems, it is the origin of the study on the development of strategic human resource management models for SMEs in the new normal life era to accommodate adjustments and changes in accordance with business operations in critical situations appropriately. It can meet the needs of consumers and partners well along with planning for the survival or growth of the organization in the long run

\section{Methodology}

\subsection{Study model}

The research model was mixed research from both qualitative and quantitative research. Developing a strategic human resource management model for SMEs in the new normal life era requires strategic human resource management to integrate human resource management into the strategic decision-making process of SMEs to enable organizations to 
manage their changing environments [7]. It is to encourage organizations to have higher potential and have a competitive advantage [8]. It is the view of people in an organization as a resource that is essential to the organization's potential and success.

\subsection{Determination of population and sample}

There are two parts of the population and the sample. Part 1: A sample group in qualitative research by collecting data from 2 methods: 1) interviews on organizational management and human resource management of SMEs in the new life era with those Entrepreneurs or executives of SMEs for 10 participants. 2) Organizing focus groups on the development of a strategic human resource management model for SMEs in a new way of life It consists of 19.Part 2: A quantitative research sample using survey research with a population of SMEs in 2018 in the total of 3,077,822 participants[4] and quantitative data from a sample of 400 peoplewas collectedby Random Sample Sampling: RSS from a database of entrepreneurs or executives of SMEsand cooperate in answering the questionnaire.

\subsection{Research tools}

The researcher used a structured interview form. The subjects of the interview were 1) an overview of the organizational management of SMEsin relation to the policies, visions, operations of the organization, including problems and obstacles in the organization's operations. 2) Strategic human resource management of SMEs related to human resource management processes from human resource planning, human resource recruitment and selection, human resource utilization, human resource retention and human resource development. The researcher used the questionnaire as a quantitative research tool. The tools used in the study were examined for the quality of the tools before being used in the actual studies for both types:

1) To verify the validity of the instrument, the investigators selected the tool's quality by finding the Item Objective Congruence index--IOC of the questionnaire.

2) The reliability tool was verified as well as trying out a questionnaire with a sample to determine reliability using Cronbach's coefficient- $\alpha$ with a sample group that was similar to the target group of 30 people. The overall reliability was 0.924 .

\subsection{Analysis and conclusion}

The data analysis and statistics used consisted of as follows: Percentage, Mean, Standard Deviation, Exploratory Factor Analysis: EFA, Principal Component Analysis: PCA and Common Factor Analysis which rotates the factor axis to be Orthogonal Rotation in Varimax.

\section{Result}

The results obtained from the research process on the development of a strategic human resource management model for SMEs in the new normal life era can be summarized according to the objectives into 3 parts as follows:

- The results of the study of conditions and strategic human resource management for SMEs in the new normal life era from the interviews can be summarized as shown in Table 1. 
Table 1. The results of the study of conditions and strategic human resource management for small and medium enterprises (SMEs) in the new normal life era from interviews with 19 qualifiers and experts.

\begin{tabular}{|c|c|}
\hline Issue & Result \\
\hline $\begin{array}{l}\text { Conditions and strategic } \\
\text { human resource } \\
\text { management of small and } \\
\text { medium enterprises } \\
\text { (SMEs) in the new normal } \\
\text { life era }\end{array}$ & $\begin{array}{l}\text { Most of the small and medium-sized enterprises (SMEs) do not } \\
\text { have clear goals and strategies for human resource management. } \\
\text { Human resource management strategies for SMEs in the new } \\
\text { normal life era include:(1) human resource planning(2) } \\
\text { recruiting and selection (3) performance management (4) } \\
\text { employee retention (5) employee relations (6) health and } \\
\text { hygiene (7) company rules and policies (8) training and } \\
\text { development (9) compensation management (10) rights and } \\
\text { benefits }\end{array}$ \\
\hline
\end{tabular}

Results of opinions on strategic human resource management for small and medium enterprises (SMEs) in the new life era can be summarized into 2sub-sections as follows:

- Results of an analysis of key components in strategic human resource management for small and medium enterprises (SMEs) in the Exploratory Factor Analysis (EFA).

The results of the analysis of the suitability of the correlation matrix between strategic human resource management and the operations of SMEs in the new normal life era found that the KMO (Kaiser-Meyer-Olkin Measure of Sampling Adequacy) value was 0.968. Chisquare value was $27084.136 \mathrm{Sig}$ value was 0.000 . In conclusion, all variables were related and suitable for use in the composition analysis of this research.

The results of arranging the number of strategic human resource management components for SMEs in the new normal life era from the Eigen Value are shown in Table 2.

Table 2. The strategic human resource management components for small and medium enterprises (SMEs) in the new normal life era from the Eigen Value that is greater than 1 both before and after the spindle rotation.

\begin{tabular}{|c|c|c|c|c|c|c|}
\hline \multirow[b]{2}{*}{ Component } & \multicolumn{3}{|c|}{ Extraction Sums of Squared Loadings } & \multicolumn{3}{|c|}{ Rotation Sums of Squared Loadings } \\
\hline & Total & $\begin{array}{c}\% \text { of } \\
\text { Variance }\end{array}$ & $\begin{array}{c}\text { Cumulative } \\
\%\end{array}$ & Total & $\begin{array}{c}\text { \% of } \\
\text { Variance }\end{array}$ & $\begin{array}{c}\text { Cumulative } \\
\%\end{array}$ \\
\hline 1 & 38.55 & 68.76 & 68.76 & 12.84 & 22.43 & 22.43 \\
\hline 2 & 2.66 & 3.54 & 72.30 & 9.12 & 17.35 & 39.78 \\
\hline 3 & 1.43 & 2.31 & 74.61 & 8.83 & 14.19 & 53.97 \\
\hline 4 & 1.21 & 2.16 & 76.77 & 7.34 & 13.46 & 67.43 \\
\hline 5 & 1.14 & 2.08 & 78.85 & 6.86 & 11.42 & 78.85 \\
\hline
\end{tabular}

From Table 2, it was found that all 5 components can be arranged as follows: Eigen Value after spindle rotation was from $6.86-12.84$ the percentage variance was between $11.42-22.43$, the cumulative percentage of variance was 78.85 .

From the results of the study of components related to strategic human resource management for SMEs in the new normal life era by bundling similar sub-organizations which can be presented in the form of a table 3as follows:

Table 3. Strategic human resource management components for small and medium enterprises

(SMEs) in the new normal life era. 


\begin{tabular}{|c|l|}
\hline \multicolumn{1}{|c|}{ Main component } & \multicolumn{1}{|c|}{ Sub component } \\
\hline human resource planning & 1) goals and plans of the organization \\
& 2) current human resource situation \\
& 3) establishing an action plan \\
\hline recruiting and selecting & 1) recruitment \\
& 2) Selection \\
\hline human resource utilization & 3) work transfer or job rotation \\
\hline & 1) job design \\
& 2) job/task planning \\
\hline employee retention & 3) performance management \\
\hline human resource development & 1) management system \\
& 2) compensation \\
& 3) employee relations system \\
\hline & 1) organizational development \\
& 2) career planning \\
& 3) Individual development system \\
\hline
\end{tabular}

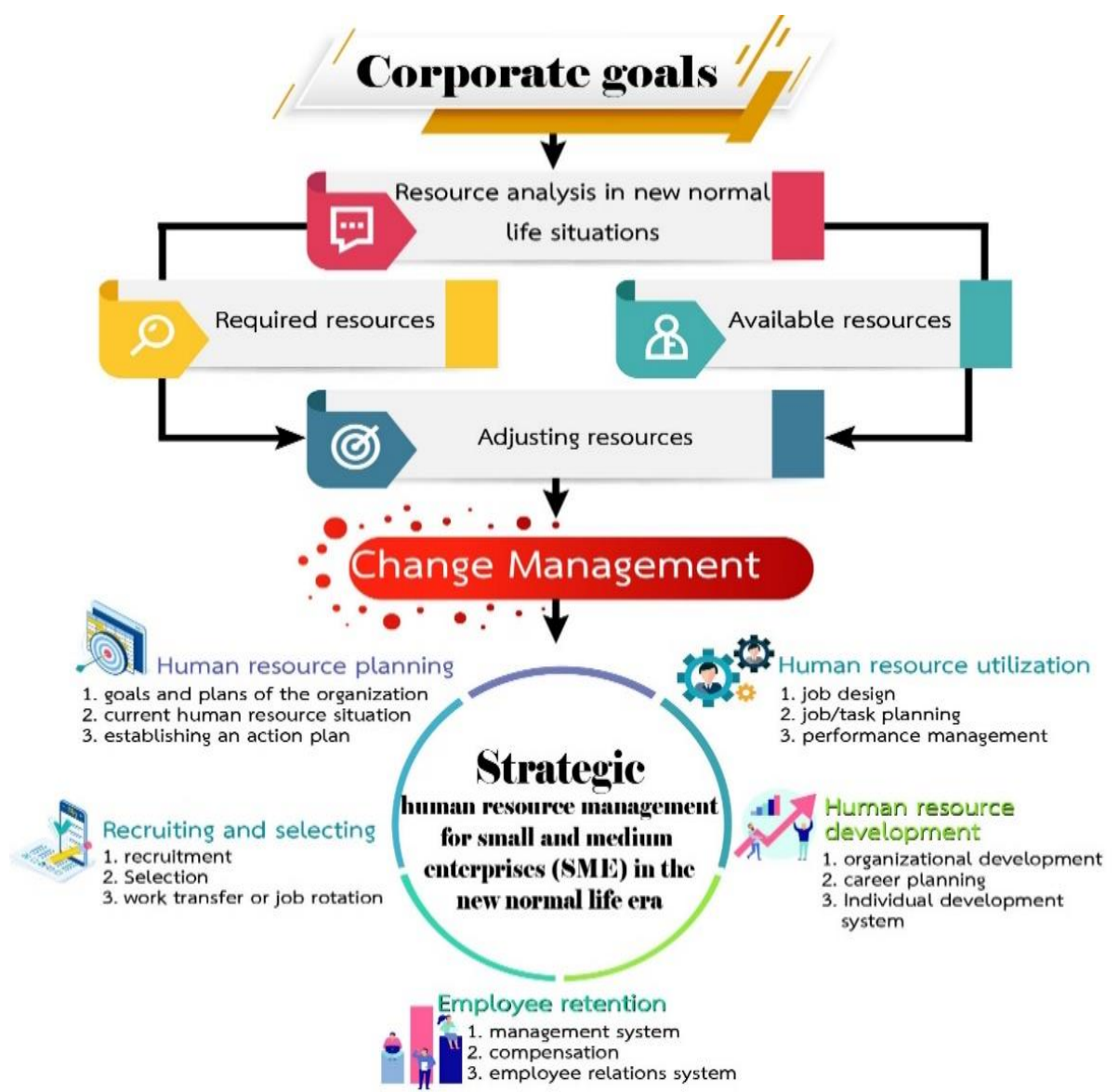

Fig. 1. Components of strategic human resource management for SMEs in the new normal life era.

- The results of the development of a strategic human resource management model for small and medium enterprises (SMEs) in the new normal life era must be considered from the goals of the organization by analysing the organization's resources from 2 parts: Resource requirements of SMEs and the available resources of SMEs. It will lead to the 
transformation of resources in line with the operations of SMEs and implement Change Management in the strategic human resource management process for SMEs in the new normal life era. From the components of strategic human resource management for SMEs in the new normal life era, 5 main components and 15 sub-components are shown in the following Figure 1.

\section{Discussion}

1. The results of the study of conditions and strategic human resource management for small and medium enterprises (SMEs) in the new normal life era found that most SMEs do not have a clear vision and mission of the company, as well as policies and/or strategies of human resource management that can be used as guidelines for the organization's business operations. Therefore, there must be a clearer guideline for managing the organization amid the changes in the new normal life that directly affect the organization by setting a vision that is an important goal in the organization's operations by planning to support the change and developing the organization according to the goals of the organization set, analysing resources in the new normal life era related to the organization, analysing the resource requirements and considering the available resources to plan to adjust the resources in accordance with the new normal life era and manage Change within the organization by taking into account internal and external factors affecting operations [9]. It is in line with the study on the organizational development of SMEs entrepreneurs in the North-eastern region of Thailand.

As part of the study, it was found that there are two approaches to developing the operations ofSMEs: (1) External environmental development is government policy and support and development of credit policy for enterprises and, (2) The internal environment of the organization, including the development of the accounting and financial system of entrepreneurs, the development of entrepreneurs' knowledge, human resource management in the workplace, marketing management, the use of subcontracting strategies, production for organizational development and the use of information technology for organizational development It shows that the conditions and needs for human resource management development of SMEs still need a lot of development. Especially in the field of human resource management in the organization.

It is the key to further development in other areas [10]. It is also consistent with the results of a study on competency for human resource managers of business organizations in Thailand, which found that human resource managers of business organizations in Thailand have 4 roles: (1) Establishing work systems and bring changes in human resource management (2) Managing strategic human resource (3) Providing advice on human resource management; and (4) Facilitating and providing human resource services that will develop the organization further.

2. The results of the study of strategic human resource management for small and medium enterprises (SMEs) in the new normal life era consist of 5 main components: 1) human resource planning 2) recruiting and selecting 3) utilization of human resources 4) Human resources retention; and 5) Human resource development and 15 sub-components that build capacity and organizational management capabilities of SMEs based on strategic human resource management principles that play an important role in the organization's management. It is consistent with the concept and principle that human resource management plays an important role in the formulation and implementation of corporate strategies [11,12]. At present, the organization will create that competitive advantage. There must be a plan to implement human resource management strategies. to create added value over competitors. Human resource management is part of the organization's strategy [13] that will enable the organization to support changes and adapt in the new normal life era to 
turn the business back to be able to continue the business. The sudden change has forced SMEs to accept change quickly and to improve their business models to respond to changes within a short time. In addition, for SMEs to be able to survive or adapt to the epidemic crisis, systems must be improved to be more efficient as well as optimizing processes and working methods, simplifying operational procedures, and minimizing previously existing inefficiencies.

3. The results of the development of a strategic human resource management model for small and medium enterprises (SMEs) in the new normal life era found that organizations need to define organizational goals, analyse resources in the new normal life, resource requirements and available resources of the organization to adjust resources in accordance with the new normal life and manage change (Change Management) about the strategic human resource management of the 5 components, namely: 1) human resource planning, 2) recruiting and selecting, 3) utilization of human resources, 4) human resources retention, and 5) human resource development to change from the old model used at the basic level to a strategy that links the work of human resource management from the vision, strategy and main goals of the organization as well as the development of the infrastructure of human resource management in a connected context to support adaptation and management of change over time. Therefore, the human resource practitioner competency development principle aims to promote knowledge.

Develop skills and competencies appropriately to be able to bring the vision and mission of the organization as a guideline for creating human resource management strategies in the organization that can meet the needs of the organization. Or have the capacity or be a business partner for executives 7 in the organization and make everyone in the organization have a common goal [14]. Therefore, the development of a strategic human resource management model for SMEs in the new normal life era focuses on human resource management which affects the success of SMEs.It corresponds to the results of the study on the development model of SMEs that affect the success in Muang district. Chonburi province found that business development that is important to the success of business operations (SMEs) overall is at the highest level. Specifically, the personnel system that is essential to the successful operation of the organization is the knowledge of the personnel, the ability of the personnel, the diligence of the personnel and the discipline of the personnel $[15,16,17]$. These factors are important driving forces in the transformation and development of SMEs to be able to operate in a changing situation that results in adaptation and in line with the new normal life era continue to operate business continuously and sustainably in the long term.

Therefore, developing a strategic human resource management model for small and medium enterprises (SMEs) in the new normal life era will be an important guideline for proactive human resource management [18] which is an indicator of organizational success to raise potential and higher capabilities and to accommodate changes caused by various situations that threaten the operation of the organization. Therefore, the organization will be stable and sustainable in the long term.

\section{References}

1. P. Kearns, HR Strategy (Oxford, Elsevier, 2010)

2. P. Boxall, Asia Pacific Journal of Human Resource 50(2), 169-186 (2012)

3. D. Ushakov et al., Public Policy and Administration 18(4), 395-404 (2019)

4. Office of Small and Medium Enterprises Promotion. Report on the situation of small and medium enterprises Inevitably in 2019 (2019)

5. S. Siriphattrasophon, Journal of the Association of Researchers 25(2), 9 - 25 (2020) 
6. D. Nevin Deniz, Procedia - Social and Behavioral Sciences 58, 914 - 923 (2012)

7. A. Karami et al., Management Research News 27(6), 50-68 (2004)

8. J. Gannon et al., Personnel Review 41(4), 513-546 (2012)

9. H.T. Van et al., Journal of International Studies 10(4), 109-118 (2017)

10. T. Promsaka Na Sakolnakorn, Organization Development of Small and Medium-Sized Enterprises in the Northeast of Thailand (Faculty of Liberal Arts, Prince of Songkla University, 2010).

11. J. Barney, Journal of Management 17, 99-120 (1991)

12. J. Pfeffer, California Management Review 40(2), 96-124 (1998)

13. M. Ansari et al., International Journal of Business and Management 7(2), 58-72 (2012)

14. B. Erasmus et al., Competencies for Human Resource Development Practitioners (University of South Africa, 2010)

15. N. Patthirasinsiri, K. Ungkanawin, Journal of the Association of Researchers 23(3), $151-164$ (2018)

16. H.T. Van et al., E3S Web of Conferences 175, 13034 (2020)

17. O. Sivash et al., IOP Conference Series: Earth and Environmental Science 272(3), 032118 (2019)

18. D. Ushakov et al., Montenegrin Journal of Economics 13(1), 171-179 (2017) 